\title{
Production risk caused by human factors: a multiple case study of thermal power plants
}

Huiyue Diao and Majid Ghorbani*

\author{
* Correspondence: majidghorbani@ \\ rmbs.ruc.edu.cn \\ Business School, Renmin University \\ of China, 59 Zhongguancun St., \\ Haidian District, Beijing 100872, \\ China
}

\begin{abstract}
Introduction: Thermal power plants are very popular in China. However, there has not been proportional research attention paid to production risk in these plants and human impact on production due to their importance in electricity generation. This study investigates production risks caused by human factors in thermal power plants and management methods to address identified human factors.
\end{abstract}

Case description: Eighteen semi-structured interviews with front-line, middle and senior managers from four thermal power plants in China were carried out in this cross-sectional inductive study. Fault tree analysis and causal network analysis are used.

Discussion and evaluation: We identify a range of production risks and human factors potentially influencing production in both negative and positive ways. We also recognize the most effective and practical relevant management methods to deal with identified human factors.

Conclusion: By investigating production risk caused by human factors through the whole production process, this study emphasizes working attitude, safety consciousness, creativity and awareness of environmental protection as essential human factors potentially influencing production risks in thermal power plants. Through our analysis, by linking human factors to different types of production risk and supplying corresponding management methods to address these human factors, we offer practical human resource management approaches in the production management of thermal power plants.

Keywords: Production risk, Human factor, Thermal power plant, Management methods

\section{Introduction}

Thermal power plants-following the definition used by the National Bureau of Statistics of China, power plants that burn fuel other than nuclear energy to produce electricity-are the most common kind of power plants globally. For example, in China in $2015,73.7 \%$ of electricity is produced by thermal power, followed by $19.4 \%$ produced by hydropower, $3.2 \%$ produced by wind power, and $2.9 \%$ produced by nuclear power (National Bureau of Statistics of China 2017). In spite of their popularity, there are few studies that focus on different risks specifically associated with thermal power plants, particularly as compared to the other types of power plants.

(c) The Author(s). 2018 Open Access This article is distributed under the terms of the Creative Commons Attribution 4.0 International License (http://creativecommons.org/licenses/by/4.0/), which permits unrestricted use, distribution, and reproduction in any medium, provided you give appropriate credit to the original author(s) and the source, provide a link to the Creative Commons license, and indicate if changes were made. 
The efficiency and safety of production in power plants are very important. The main product of power plants is electricity, a critical component of modern life. Accidents and improper behavior in power plant production procedures may have significantly negative impacts from air and soil pollution to destruction, death and long-term impacts on surrounding communities and environment (Friedman 2011; Arab et al. 2015; Rodriguez-Iruretagoiena et al. 2015; Ofori-Parku 2016; Tanić et al. 2016). Many researchers recognize the importance of efficient and safe production in power plants and much research has been done on managing risk and reducing uncertainty in production procedures (e.g., Feili et al. 2013; Islam and Nepal 2016; van Kooten et al. 2016; Zhao et al. 2016). However, since different energy sources have different production procedures, research findings are specific to the type of power plant under consideration. For example, in wind power systems, one of the greatest challenges is the energy source supply process, which relies on sufficient wind power (Karki et al. 2012) and wind speed forecasting (van Kooten et al. 2016). On the other hand, in a thermal power plant system, besides the general supply (quantity) of heat, the quality and price of the energy source also involve risk (Zhao et al. 2016; Majoumerd et al. 2017). In contrast, once the construction of a hydropower station is completed, the risk does not lie in the energy source selection procedures, but in the environmental factors influencing the steady flow of water and the surrounding environment's stability (Ji et al. 2015). Also, in comparison with a nuclear power generation system that requires human input mainly in the human-system interface of the control systems (Carvalho et al. 2008; Suwazono et al. 2015), in a thermal power generation process, which is of a lower automation level and is less environmentally friendly (Wolf 2015), workers are more exposed to the energy sources (Ren et al. 1998). This is mostly because human input is more essential in, for example, making decisions regarding the desulfuration and denitration procedures that could have potential environmental implications (Liu et al. 2017). Thus, it is imperative to pay more attention to the human factors of the electricity production process in thermal power plants.

Compared with production risks of a technical nature, human factors in production risk are more uncontrollable because of individuals' unique personalities and ideas. Researchers have identified the influence of human factors on production in modern agriculture (Vollmer et al. 2017), in manufacturing (e.g., Govindaraju et al. 2001; Bevilacqua and Ciarapica 2018), and in the nuclear power industry (e.g., Le Bot 2004; Carvalho et al. 2008; Vaurio 2009; Teperi et al. 2017). Studies have shown that human factors are a potential source of risk regardless of the level of process and production automation in an industry. The present findings are not enough for human factors in workers' individual production judgments within a system with less automated controls and fewer potential threats as we see in thermal power plants. Human behavior in thermal power plant production procedures includes not only making decisions in humansystem interfaces as well as crisis and accident management but also energy source selection, ordinary ground inspection, and environmental conservation. A thermal power plant provides an outstanding context to examine the role of human factors in production risks and discuss corresponding management methods to address these human factors. Hence, this is a timely study to investigate human factors influencing production procedures in thermal power plants. 
The main purposes of this case study on thermal power plants are: (1) to investigate which human factors may cause production risks, (2) to identify the sources of key human factors causing production risks, and (3) to evaluate methods used by managers in dealing with human factors causing production risks.

\section{Literature review}

\section{Production and other risks in power plants}

Our definition of production risk follows the general definition of risk as any potential consequence of uncertainty (Ward 2005). We use this definition in the context and process of production to refer to production risk. According to this definition, potential consequences of uncertainty include, but are not limited to, the slowing, stopping, speeding up, hindering or deviating from the normal process of production. This is a description of a risk variable by which even a small deviation from its projected value is critical to the project outcome (Potluri and Rajan 2010). It is closely related to production efficiency and is a major source of output variability (Tiedemann and Latacz-Lohmann 2013). In production analysis, production risk is associated with general uncertainty (Antle 1983) and can be depicted by output variance (Vollmer et al. 2017). Production risk is often caused by uncertain elements such as unpredictable weather or employee behavior (Chavas et al. 2010).

Many researchers have investigated potential risks in a power plant. Due to the different production processes in power plants using different energy sources, the majority of research focuses on risks in one type of power plant-nuclear. An examination of diversified risks is essential in power plants with different energy sources. For example, for renewable power plants, intermittent supply is a major issue. Amato et al. (2011) use a fault tree to analyze how the setting of solar power plants impacts the frequency and severity of risks related to business interruption and assets. Karki et al. (2012) have developed a method to help recognize the variability in wind and quantify the risk in wind power commitment. For hydropower plants, risk is most severe during the construction phase. Ji et al. (2015) have developed a risk assessment model that takes into account the characteristics of the project, natural factors and anthropogenic factors in the construction of hydropower plants. Zhou et al. (2014) apply an analytic network process and causal graphs, using data from 186 cases of related accidents to determine that "safety supervision and inspection" and "organization and responsibility" are the most essential human factors related to safety risks in hydropower plant construction projects.

Risks in nuclear power plants have attracted the attention of many researchers because of large scale devastating disasters such as the Three Mile Island accident in 1979, the Chernobyl nuclear accident in 1986 and the Fukushima Dai-ichi nuclear accident in 2011. Scholars have examined risk in nuclear power plants from multiple angles, including construction risks (Wang et al. 2011), risks of refueling leakage (Rohrer and Nierode 1996), and risks in systems operation (Smith 1998; Le Bot 2004; Carvalho et al. 2008; Jou et al. 2011; Lee et al. 2012; Anuar and Kim 2014; Teperi et al. 2017). Risks in systems operation are further divided into components outage, initiating events (Smith 1998), human error-especially individual psychological error (Le Bot 2004), as well as human factors in human-system interfaces (Carvalho et al. 2008; Anuar and Kim 2014), in reporting and analyzing 
operational events (Teperi et al. 2017), and in the main control room (Jou et al. 2011; Lee et al. 2012).

Besides, investigation on risk in thermal power plants so far has focused on non-human related factors including those in construction, fuel supply, market demand (Potluri and Rajan 2010), operation conditions (Zhang et al. 2006), monitoring systems (Chang et al. 2010), and environmental policies (Abadie and Chamorro 2009). Some researchers have conducted comparative studies in different kinds of power plants, and focused on distinctions in risks due to differences in production processes (e.g., Verbruggen 2008; Wolf 2015; van Kooten et al. 2016). These studies reveal that while risk at nuclear power plants could potentially lead to major catastrophic accidents, in general, thermal power plants appear to be more troublesome. Regardless of the magnitude of trouble, as the most popular kinds of power plants in China (National Bureau of Statistics of China 2017), thermal power plants will continue to be an important part of China's power generation industry for some time, and therefore these risks will need to be recognized and managed. For example, Ren et al. (1998) note that, even with technical and management improvements, pollution from coal and potential accidents in the electricity generation chain make the health risks from the coal-fired power industry approximately 4.4 times higher than the nuclear power industry. Employees in coal-fired power plants face not only higher levels of physical health risks but also more mental health problems than nuclear workers (Parkinson and Bromet 1983).

Despite the prevalence of problems caused by thermal power plants, in the wake of catastrophic accidents in the nuclear power industry, opposition to nuclear energy has increased and some countries, such as Germany, have proposed shutting down or phasing out nuclear power plants even though coal-fired plants continue to release a great amount of carbon dioxide and renewable energy is not yet ready to replace all coal-fired plants (Wolf 2015). Given the proposed shutting down or phasing out, thermal power plants' production efficiency will become even more important. By considering the cost, prices, operation and potential accidents, Verbruggen (2008) examines the appropriateness of nuclear, fossil fuels and renewable sources as future sources for power generation, and suggests that the level of acute operational risks is high, manageable and tiny in nuclear, fossil fuels and renewable sources respectively, that renewable sources can be more financially competitive than nuclear sources, and that fossil fuels have extreme negative impacts on the climate and environment. Renewable energy is a better option than thermal power and nuclear power, but power plants that generate electricity using renewable energy such as wind power plants, cannot be supplied with enough input at all time (van Kooten et al. 2016) and there are currently not sufficient numbers of them in operation to replace thermal and nuclear power plants in electricity generation.

Considering the importance of thermal power plants to electricity supply and the importance of their production efficiency to environmental protection (Liu et al. 2017), more research is needed on thermal power plant production efficiency and risks related to production procedures.

\section{Production risks}

Production risks are caused by uncertainties (e.g., unpredictable weather or employee behavior) in production processes (Chavas et al. 2010). Even a small deviation from the estimated value of any type of production risk is critical to the project outcome (Potluri 
and Rajan 2010). Understanding production risks in production systems helps estimate production output (Tiedemann and Latacz-Lohmann 2013), better risk communication with less amplification, and attenuation of the consequences of these risks (Ofori-Parku 2016), and adjustment of production decisions, in this case, further contribute to electricity supply network planning. Understanding and managing the sources of these risks helps bettercontrol production variations (Sobhani et al. 2017).

Production risk, in detail, lies in all variables, such as humans, materials, and machines, contributing to production processes (Govindaraju et al. 2001). Based on our search of existing studies, the identified causes of production risk include procedure usage, fatigue, knowledge, experience, time pressure (Sheikhalishahi et al. 2017), turnover (Vaurio 2009), efficiency of implementing orders (Bevilacqua and Ciarapica 2018), mental pressure (Jou et al. 2011), maintenance planning (Krishnasamy et al. 2005), ergonomic work conditions, discomfort, pain, stress, reduced visual, hearing, smell and tactile abilities (Govindaraju et al. 2001), equipment failures (Lavasani et al. 2015), monitoring systems (Chang et al. 2010), land, labor (Tiedemann and Latacz-Lohmann 2013), weather (Karki et al. 2012), environmental communication, risk communication (Ofori-Parku 2016), and risk attitude (Vollmer et al. 2017). Among these causes, equipment failures, maintenance planning (Krishnasamy et al. 2005) and monitoring systems (Chang et al. 2010) are particularly examined as causes of production risk in thermal power plants in the literature.

Research on risk in power plants also investigates the causes for the loss (e.g., Krishnasamy et al. 2005; Bevilacqua and Ciarapica 2018), delay in production (e.g., Sheikhalishahi et al. 2017), and even production cessation (e.g., Carvalho et al. 2008). However, as indicated by the definition of production risks as sources of output variability (Tiedemann and Latacz-Lohmann 2013), a potential rise in output can also be a consequence of production risk. We recognize that one cause in particular is the human factor.

\section{Human factors and their effects}

Human factors, as inputs in a quasi-technical process (Leenstra 2017), describe interactions of individuals with each other, with equipment and facilities and with management systems (Amir-Heidari et al. 2015; Chidambaram 2016). They consist of a subset of soft factors in production processes (Vogt et al. 2010) and influence production efficiency and safety (Theophilus et al. 2017). In contrast to machines (Derksen 2014), human factors are unpredictable and changeable (Xie and Guo 2018) and are therefore a type of workplace risk (Sobhani et al. 2017). For example, Baayen et al. (2017) show that human factors such as familiarization with tasks, fatigue, learning, and attentional fluctuations all impact the outcome of any production process.

Both human factors and technical factors are important in production (Toor 2009). Even in industries with very high levels of automation, such as the nuclear power generation industry, where control procedures are done by humans, machines, or a combination of human and machine (Anuar and Kim 2014), human factors have proved to be essential for production (Le Bot 2004; Carvalho et al. 2008; Vaurio 2009). Human factors in power plant production impact operational procedures, maintenance programs, safety procedures (Orme and Venturini 2011), emergency management (Jou et al. 2011) and so on. Human factors connect 
operations management and human resource management. Managing human factors shapes a production system while human resource management chooses and promotes people who suit the system (Neumann and Dul 2010). Human performances, such as working "speed" and "accuracy," can influence quality of production and be influenced by people's "physical," "psychological," "mental" and "sensory" factors (Govindaraju et al. 2001, p. 362). Human factors can also be divided into organizational-level human factors, also called organizational factors (Chidambaram 2016), such as organizational climate and organizational processes, and individual-level human factors, such as routine violations, physical limitations (Xie and Guo 2018), knowledge, experience (Sheikhalishahi et al. 2017), mental pressure (Jou et al. 2011), training levels, human-machine interfaces, quality of information (communication), and lack of supervision (Bevilacqua and Ciarapica 2018).

\section{Managing human factors in production}

The majority of human factor researchers focus on the negative side of this construct. In production studies, some of them hold the idea that human factors are among the primary factors in accidents (Vaurio 2009; Chidambaram 2016; Dan et al. 2017; Theophilus et al. 2017; Xie and Guo 2018), production losses (Orme and Venturini 2011; Sheikhalishahi et al. 2017) in both routine, emergency operations (e.g., Le Bot 2004; Vogt et al. 2010; Jou et al. 2011; Xie and Guo 2018) and, therefore, try to provide useful management methods to reduce threats caused by human factors. The proposed methods include implementing management of change programs (Amir-Heidari et al. 2015), shifting management and knowledge management (Sheikhalishahi et al. 2017), focusing on corporate safety culture and safety awareness management (Xie and Guo 2018), providing high quality training (Amir-Heidari et al. 2015), improving human-plant interface and detection of latent errors, defining tasks consistent with human nature, separating tasks to avoid repeated errors, encouraging for reporting errors (Vaurio 2009), and requiring workers to follow correct processes (Xie and Guo 2018).

Human factors also have the potential to bring about unplanned and unforeseeable beneficial outcomes (Leenstra 2017) and improve performance (Neumann and Dul 2010; Sobhani et al. 2017). For example, by enhancing the interactions of humans with their work environment, managing human factors is a way to increase production safety (Vogt et al. 2010) and product quality (Govindaraju et al. 2001). However, scholars mostly focus on negative rather than positive implications of human factors and more research on the positive side of human factors in production is still needed.

There is still relatively little research on the production efficiency and the effects of human factors production on thermal power plants. Given that assessing risks and the sources of risk in plants cannot be independent from understanding the operating procedures of the plant (Orme and Venturini 2011), thermal power plants, with fewer automated control systems and fewer hazards, offer a different context from nuclear power plants, which so far have been more commonly the focus of research on human factors (e.g., Vaurio 2009; Jou et al. 2011; Teperi et al. 2017). Crucial inputs into production procedures, with negative and positive effects on production risks and sources of output variability (Tiedemann and Latacz-Lohmann 2013), and corresponding management approaches need to be examined. 


\section{Methodology}

\section{Case study method}

When generalization misses unique insights into the research focus, interpretivism can be a useful method (Saunders et al. 2009). The key target of this research is analyzing obtainable subjective opinions about production risks caused by human factors in thermal power plants from a population of managers. Therefore, instead of a positivist approach, which focuses on the objective, an interpretivist approach concerned with subjective issues is more suitable for this study.

As noted in Le Bot's (2004) discussion of the reliability and validity of data, qualitative data is more suitable to human factor analysis than quantitative data. As this study examines current conditions not involving time variables or dynamic changes, a cross-sectional approach is used instead of a longitudinal method. Since most thermal power plants in China share similar production procedures, in this research we chose four thermal power plants as a representative sample to conduct a multiple case study.

The data collection and analysis followed the following four steps: (1) 18 managers from four thermal power plants (Company A, Company B, Company C and Company D) were interviewed about production risk, production risks caused by human factors, individuals' jobs in production, human factors influencing production performance, elements influencing human factors and methods to manage human factors in order to control production risks in thermal power plants; (2) production risks caused by human factors in different production units were categorized; (3) characteristics of human factors causing production risks and their sources were analyzed; (4) the suitability of management methods in addressing human factors, proposed by managers at different levels and from different companies, to were evaluated.

\section{Data collection}

Semi-structured interviews are used for data collection. Interviews allowed us to have a broad picture (Li et al. 2017), go deeper (Yan et al. 2009; Wang 2010) and understand factors that otherwise we would not have been able to uncover. The interviewees were asked to provide examples and those examples were used to better understand interviewees' responses. Thus, most bias or misunderstandings during data collection were reduced. As this study seeks to understand and compare not only methods used by managers at different levels in the same company but also methods used by managers at the same level from different companies, a multiple case study approach is applicable (Yin 2003).

\section{The companies}

Company A, Company B, Company C and Company D are all thermal power plants in China. Company A and Company D are located in Henan province, while Company B and Company $\mathrm{C}$ are located in Beijing municipalityand Shandong province respectively. Company A, C and D use coal as their main source, while Company B uses natural gas. By 2012, when the interviews were conducted, Company A, established in the 1980s, had about 600 employees; Company B, established around 1970 had about 300 employees; Company C, started operations around 1990 had approximately 800 employees; and Company D, built in the 1950s, had about 400 employees. The four companies share a similar organizational structure that is common among all thermal 
power plants in China with around $15 \%$ of their employees being front-line managers (team leaders), 5\% middle level managers, $2 \%$ senior managers, and the remainder are general employees at various levels. As an example, Company D's organizational structure is shown in Fig. 1.

\section{Face-to-face interview process}

A sample, representing managers in thermal power plants in China, was selected by purposive sampling. To collect data in this research, 18 interviews were conducted in 2012. The interviewees were from various levels of management working in different departments and with different functions. Several interviews in each power plant were carried out. Each time, the shift-manager for that particular level of management at the time was approached for interviews. All interviews were carried out in Chinese, and interview notes were translated from Chinese to English by the research team. Table 1 shows the detailed information of interviews and interviewees. The names of interviewees are closed to protect their privacy. As can be seen in Table 1, we have given each employee a name that represents their company name, level of management and unique identifying number.

A-SM-1 and A-SM-2 both hold business management doctorate degrees from top universities in China with more than 10 years' experience in the field. By interviewing them, we explored senior managers' idea about production, risk and human factors as well as gained a broad picture about our research scenario. B-SM-3 also holds a business management doctorate degree and was knowledgeable about the production processes using energy sources other than coal. The five managers (C-SM-4, C-MM-5, C-MM-6, C-MM-7, and C-MM-8) from the third plant, Company C, were in senior or middle level management, were familiar with the whole production process and did not just focus on one production procedure. Their answers enabled us to see the similarities and differences between managers at different levels. Ten managers in different positions in the fourth plant, Company $\mathrm{D}$, were interviewed to ensure we captured a wide range of opinions from different levels of management. Among the ten managers, one (D-SM-15) was a senior manager, four (D-MM-13, D-MM-16, D-MM-17, and D-MM-18) were middle level managers from four different departments, and the remaining five (D-FM-9, D-FM-10, D-FM-11, D-FM-12, and D-FM-14) were leaders in five front-line sections. Three of the front-line managers, where production risks are most likely to occur, were experienced employees, who had worked in thermal power plants for more than 10 years, while the other two (holding bachelor degrees) had been

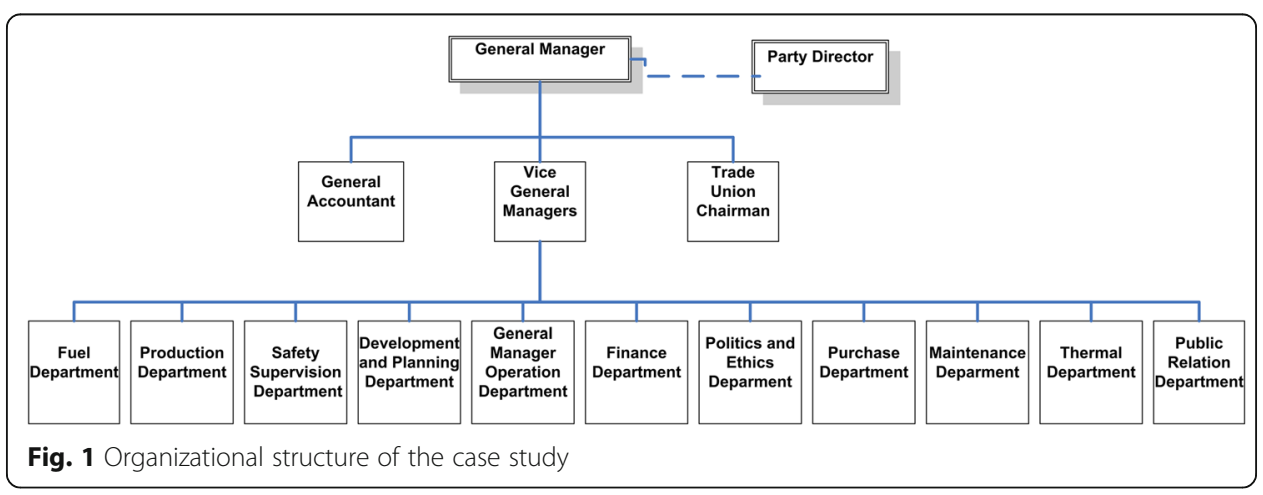


Table 1 Information of Interviewees

\begin{tabular}{lllllll}
\hline $\begin{array}{l}\text { Code } \\
\text { name }\end{array}$ & Company & Age & Gender & Education & Position & $\begin{array}{l}\text { Length of interview } \\
\text { (minutes) }\end{array}$ \\
\hline A-SM-1 & A & 36 & Male & PhD & Senior manager & 75 \\
A-SM-2 & A & 48 & Female & PhD & Senior manager & 50 \\
B-SM-3 & B & 44 & Male & PhD & Senior manager & 59 \\
C-SM-4 & C & 38 & Male & Master & Senior manager & 32 \\
C-MM-5 & C & 39 & Male & Bachelor & Middle level manager & 80 \\
C-MM-6 & C & 45 & Male & Bachelor & Middle level manager & 36 \\
C-MM-7 & C & 36 & Male & Master & Middle level manager & 33 \\
C-MM-8 & C & 40 & Male & Bachelor & Middle level manager & 42 \\
D-FM-9 & D & 40 & Male & Vocational college & Front-line manager & 65 \\
D-FM-10 & D & 35 & Female & Vocational college & Front-line manager & 45 \\
D-FM-11 & D & 25 & Male & Bachelor & Front-line manager & 52 \\
D-FM-12 & D & 52 & Male & Vocational college & Front-line manager & 37 \\
D-MM-13 & D & 34 & Female & Bachelor & Middle level manager & 57 \\
D-FM-14 & D & 28 & Male & Bachelor & Front-line manager & 45 \\
D-SM-15 & D & 51 & Male & Master & Senior manager & 58 \\
D-MM-16 & D & 34 & Female & Bachelor & Middle level manager & 41 \\
D-MM-17 & D & 31 & Female & Master & Middle level manager & 55 \\
D-MM-18 & D & 36 & Male & Professional college & Middle level manager & 40 \\
\hline & & & & & &
\end{tabular}

working for the plant for more than 2 years. The assumption is that managers with different levels of work experience and education have different insights into operation procedures and risk in the plant.

The list of interview questions used in semi-structured interviews is provided in Appendix. These questions were purposefully and carefully designed so that each can capture a particular construct. Many questions were followed by follow-up questions, where needed. For example, a question was designed to identify the kinds of risks usually noted by managers and whether those managers had a good understanding of production risk. Another question was designed to reveal managers' attention when they were trying to deal with a particular production risk. To verify the reliability of their answers, managers were required to give cases in practice for successful or unsuccessful methods to support their evaluations. Being asked to give examples, managers may rethink their answers and the consistency of their answers can be examined by the interviewers.

\section{Data analysis methods}

Following three steps of data simplifying, data organizing and conclusion drawing and testing, as suggested by Miles and Huberman (1994), all interview notes were analyzed. In the early step analysis, key words in interview notes were coded according to their relationships with questions and other key words. With the preparation in early step analysis, data were organized according to relationships between key words.

In the data organizing step, several methods are used for reaching different research objectives. Firstly, by coding and summarizing answers to the questions (1) to (4), managers' attitude about the link between production risks and human factors is illuminated. Secondly, the answers to questions (2) and (3) are analyzed with fault tree 
analysis to meet the objective-what production risks can be influenced by human factors in production procedures. Fault tree analysis is a popular method to explain how things go wrong in process research (e.g., Amato et al. 2011; Ramesh and Saravannan 2011; Chen and Wang 2017) which is an adequate tool to identify related hazards in complex systems (Lavasani et al. 2015). The weakness of using fault tree analysis to show the influencing network is that only negative influences can be expressed. Therefore, the positive influences are discussed separately. Thirdly, we use causal networks to put several people's cause maps together and to show factors and consequences, as suggested by Miles and Huberman (1994). Causal networks, specifically, are used for analyzing causal relationships between sources of human factors, and those between human factors and production risks. Answers to questions (4) to (9) are used to do analysis in this step. Fourthly, answers to the rest of the questions contribute to the last objective. By categorizing managers and coding their opinions to find methods for managing key human factors, methods supported by and useful to different groups are evaluated.

\section{Results}

Interview responses involve four main parts: human actions in production procedures; human factors in production-what human behaviors or characteristics may affect production efficiency; issues influencing human performance-why humans behave as they do; and methods for managing human factors-how production risks caused by human factors are managed.

We organize the results in three sections: (1) production risks caused by human factors, in which we recognize human factors and how they impact production; (2) the suitable management methods to address each human factor, which depend on the circumstances in a particular power plant; and (3) the evaluation of all human factors and corresponding managers' methods to deal with them.

\section{Production risks caused by human factors}

A summary of production risks and corresponding human factors is provided in Table 2. According to the interviewees, ten procedures of the production process are related to human factors. The ten production procedures include: raw material (e.g., coal, gas) selection, equipment maintenance, abnormal situation treatment, human-machine interfaces, monitoring in control rooms, ground inspection, detailed technical improvements, manual operation, equipment purchase, and environmental conservation decisions. Nine human factors are identified as influencing production procedures in thermal power plants. The nine human factors are: efficiency of implementing orders, creativity, turnover, professional skills, safety consciousness, violating operation procedures, psychological and health conditions, environmental awareness, and working attitude. Different elements of the main human factors are analyzed in detail below.

\section{The potential negative side of production risks caused by human factors}

To indicate the passive impacts of production risks caused by human factors in thermal power plants, a production fault tree is presented in Fig. 2. Instead of covering all events that may cause production failures, the fault tree only consists of human jobs, 


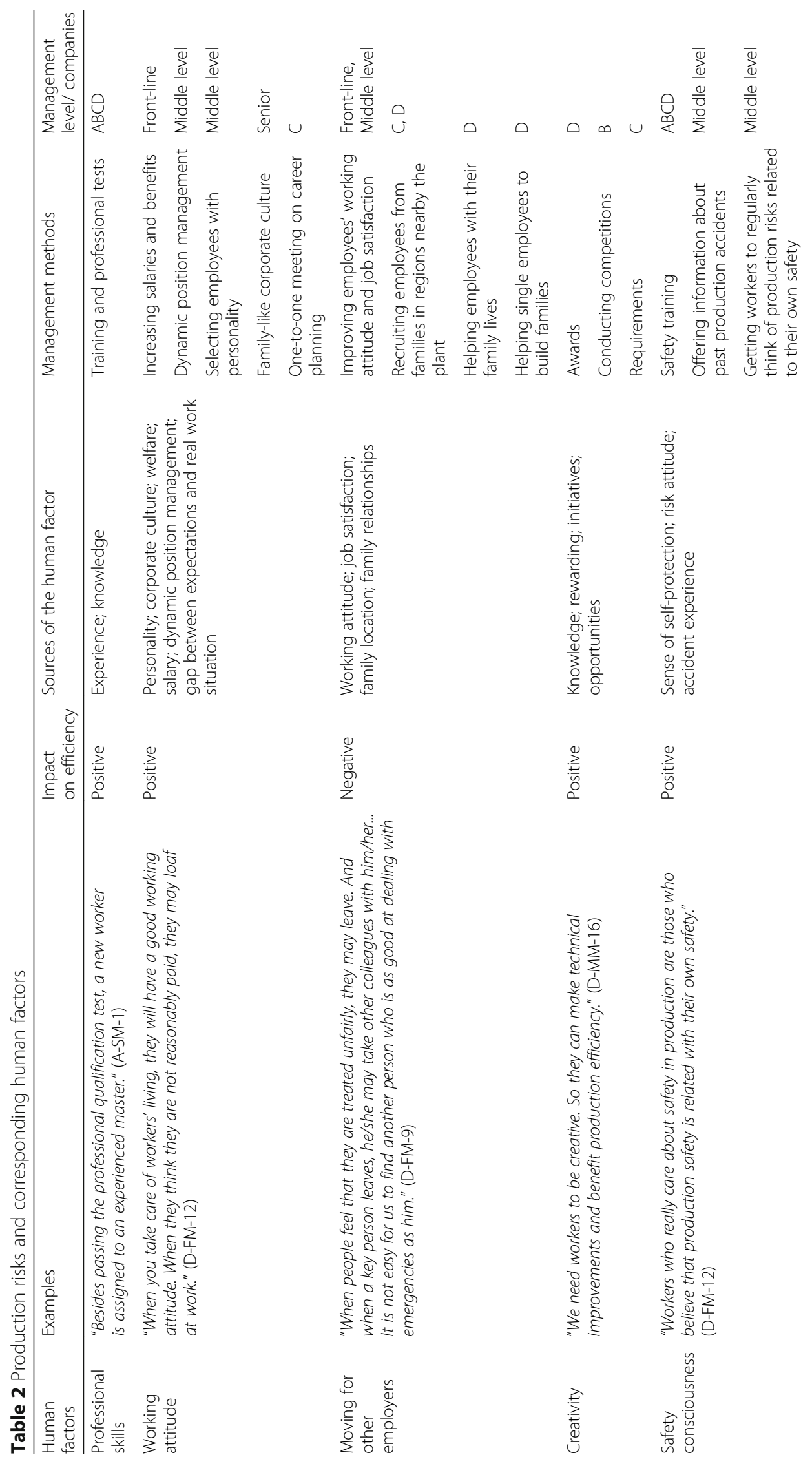




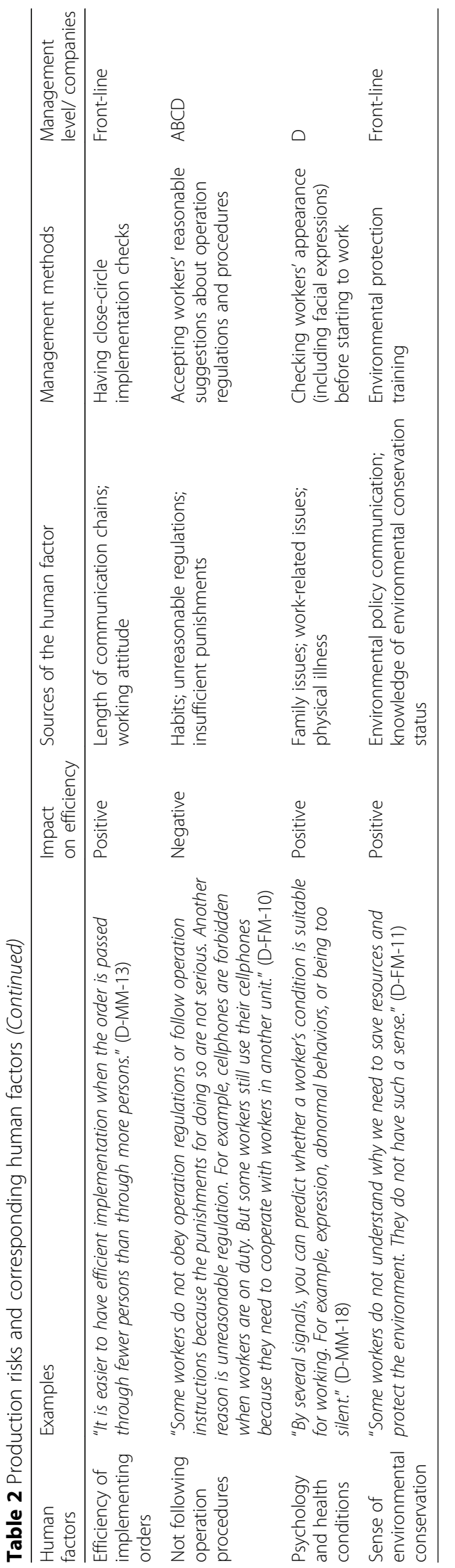




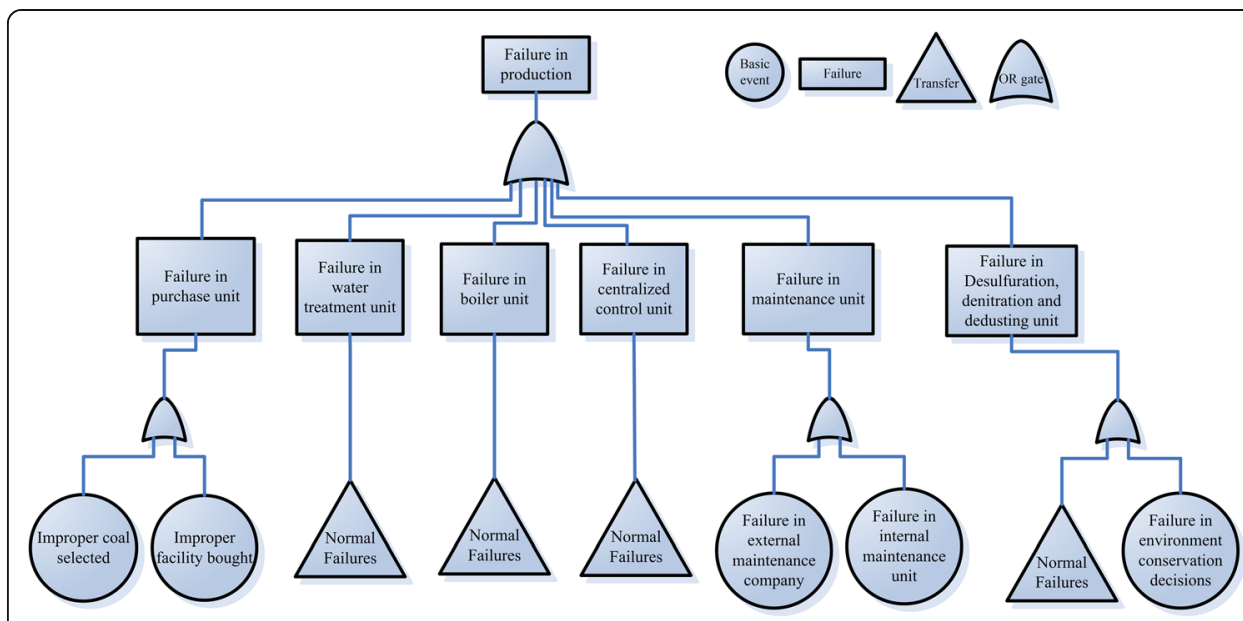

Fig. 2 Production fault tree with human jobs in thermal power plants

identified by the interviewees, in each production unit. Figure 3 shows failures which may happen in production units, where several human jobs are involved.

As shown in Fig. 2, the main production risks caused by human factors in the purchase unit are risks in raw material (e.g., coal, gas) selection and equipment purchase. If improper fuel sources or equipment, which cannot meet the production requirement, are bought, power generation efficiency may be lower than the standard and other equipments could be damaged by the poor quality of coal or equipment purchased.

All kinds of normal failures, potential consequences of risks in manual operation, in abnormal situation treatments, in human-machine interfaces, in monitoring in control rooms, in technical improvements and in ground inspection, as shown in Figs 2 and 3, may happen in water treatment units, boiler units, centralized control units, and desulfuration, denitration and dedusting units. However, the probability and impact of each risk in different units are different. Due to the automation level in the water treatment unit of the plants, more manual operation procedures are required in this unit than in the other three units. As emphasized by one manager (D-MM-18), "Mistakes in

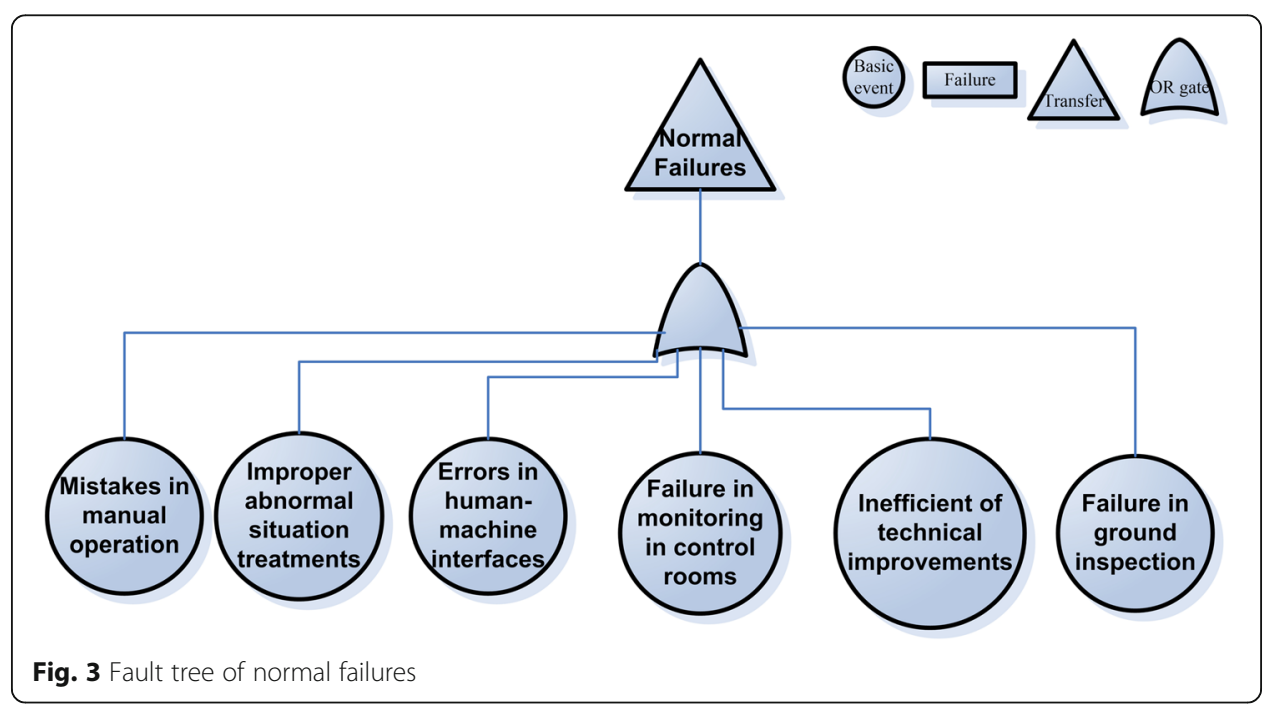


manual operation are less harmful than human errors in human-machine interfaces, because, in a lower-level automated process, chain-reactions are not likely to happen so quickly and people may have more time to correct the error." Two other managers (B-SM-3, D-FM-10) also made similar statements. Therefore, the risk of manual operation in water treatment procedures is higher, but the impact is less significant than in the other three units.

On the other hand, the risk in monitoring in control rooms and working at human-machine interfaces is higher in the boiler unit and central control unit. The probability of production safety accidents is very low because the automatic process has alarms for abnormal situations and its self-protection programs. For instance, D-FM-9 mentioned: "Human errors or equipment failure may set off the alarms. If the alarms are not treated properly, a chain-reaction may happen. Once the failure goes beyond a certain extent, the self-protection system will be active and the generation process will shut down." In other words, system shutting-down is a potential consequence of risk in abnormal situation treatments. It makes abnormal situation treatments especially important, given that operation system shut down is treated as one of the two most serious problems, of which the other is personnel safety, as mentioned by A-SM-1, A-SM-2, and B-SM-3.

Problems with facilities that might occur during generation procedures need to be identified during ground inspections in all generation units as the maintenance work is done either by an external maintenance company or an internal maintenance department. Although using an external maintenance company can simplify the work for the plant, an internal maintenance department, which is used by Company D, can be more controllable. The main problem in maintenance units, as identified by D-FM-12, is failing to discover the real problem during maintenance. When employees during routine maintenance fail to find any existing problem, the potential hazard is not discovered and more serious problems may occur in the future. Therefore, experienced and skillful workers, who hold comprehensive technical skills to reduce the risk of misjudgment or failure in problem discovery, are especially needed in maintenance units. However, in such a case where there are experienced and skillful employees positioned in maintenance units, these units are more likely to be affected negatively by these key workers' leaving.

As a unit in charge of environmental conservation in a thermal power plant, the desulfuration, denitration and dedusting unit faces both risks potentially causing normal failures and risks in environmental conservation decisions. If the production of a power plant fails to meet the emission standard required by relevant policies, a power plant can face severe penalties or even be forced to stop production. Although procedures in other units can also contribute to environmental conservation, whether the production can meet the required standards mainly depends on procedures in this unit, where the workers' sense of environmental conservation is more important than in other units.

\section{The potential positive side brought by human factors}

Human activities in production procedures also have the potential benefit for production. In the purchase unit, as stated by the senior manager of Company D, D-SM-15, "A clever and loyal employee, who tries to maximize plant profit, pays a reasonable price for better-quality coal." Similar things may happen in equipment purchases. 
In all units involving human activities in systems control, workers' proper environmental conservation decisions help save resources, reduce production costs and improve production efficiency. Along the same lines, D-FM-11 stated: "If a worker adjusts the input quantity of coal in time, then coal is cleverly saved. If a worker turns down the flow of water when there is no need to have a heavy flow, water is saved."

Another potential positive effect on production, brought by human factors, lies in technical improvements. As an opportunity to make production procedures more efficient or more cost-effective, being creative and making technical improvements are often encouraged. A proposed procedure or technical improvement suggestion, after careful evaluation and examination, being broadly applied to relevant procedures, in most cases, can bring a rise in production.

Potential consequences of ground inspection also have a positive side. B-SM-3, for example, said: "The most valuable characteristic of an experienced ground inspection worker is that he can predict potential problems before things are as wrong as an automatic system can pick out."

Another manager, D-MM-18, offered an example to illustrate how human factors benefit production by preventing potential threats.

"An employee in charge of ground inspection knows that, in winter, wild animals like to hunt for their food near equipment in our power plant [where it is warmer and there is good shelter for prey]. This makes that equipment more prone to be damaged in winter than in summer." (D-MM-18)

As such, more detailed inspection by this employee in winter catches damage to equipment timely and has saved the plant from potentially more serious damage several times.

\section{Human factors and corresponding management methods}

The main human factors, identified by interviewees, influencing almost all production risks except risks in environmental conservation decisions, are relevant professional skills and working attitude. Professional skills can be improved by training and professional tests, while working attitude is more psychological and spiritual, which is difficult to control and qualify. We, therefore, made more queries on the components and factors influencing working attitude. Questions, such as "what factors influence one's working attitude," "how do these factors contribute to one's working attitude," and "what are the sources composing one's working attitude" were asked. Working attitude, determining how much employees care about benefits to the plant, can be influenced by several elements. Figure 4 shows the causal network for working attitude.

Experienced and skilful workers leaving the company for other employment opportunities is the most troublesome human factor influencing abnormal situation treatment risk. Fifteen of the 18 interviewed managers stated that they do not want to lose these key persons. It is difficult to find employees who have rich front-line experience, know how to deal with abnormal situations, can make proper judgments of what is wrong, and can predict what may happen in unforeseen conditions. If an employee has a positive working attitude and is satisfied with the current situation, it is unlikely for him/her to change his/her job. Besides working attitude, family factors, such as family 


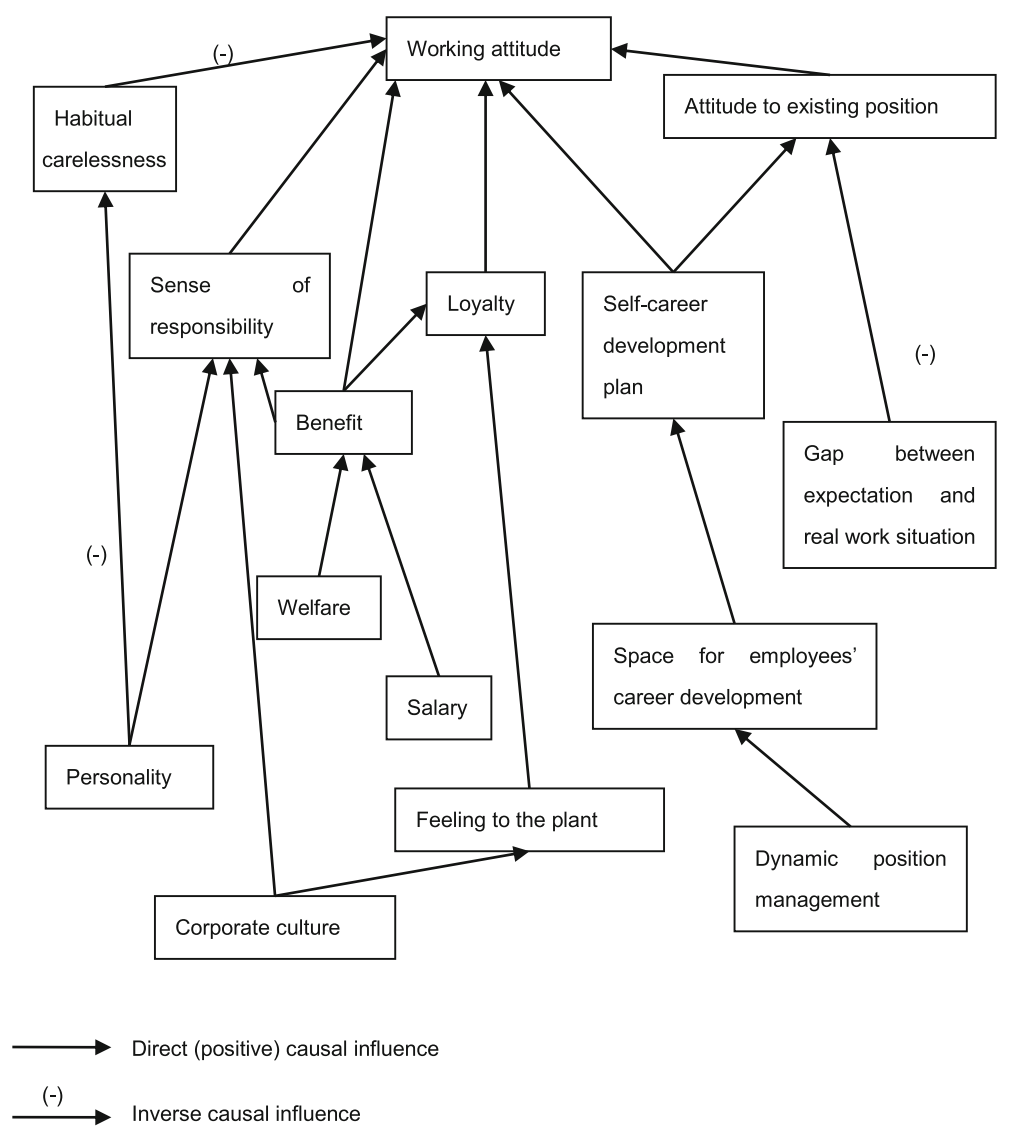

Fig. 4 Causal network for working attitude

location (i.e., being together or in separate geographic locations with periodical visits) and family relationships (i.e., feeling estranged, closed or distanced) are identified by six of the interviewees as determinants of key persons' loyalty or likelihood of leaving for other employment opportunities. Besides recruiting employees from families that are in the city where the plant is located, the trade union of Company D helps employees with their family lives and helps single employees to build families locally.

Technical improvements in a power plant mainly depend on employees' creativity, professional skills and working attitude. Monetary reward is a popular way used by all the plants studied. Four of the five front-line managers made it clear that detailed technical improvements can be developed by front-line workers when they feel that work demands are unreasonable. In other words, detailed improvements in production procedures are likely to be generated from employees' initiatives. Also, employees need opportunities and paths to communicate their ideas. One manager, B-SM-3, noted that monetary reward is given to employees that provide practical improvement suggestions during a plant-wide competition, which is organized twice a year in Company B. Usually, rewarded suggestions are implemented. Another manager, C-MM-8, also said that all workers were required to give suggestions once a year in Company C. Compared with Company D, which sets rewards to encourage employees' creativity, Company B uses competitions to remind employees to think about areas of improvement, and Company $\mathrm{C}$ requires or in 
some ways "forces" employees to make suggestions. Having more workers think about areas of improvement may improve the production procedures, but it may also lead workers to be critical and feel unsatisfied with what they have.

Safety consciousness, efficiency of implementing orders, violating operation procedures and psychological and health conditions are identified as human factors related to production risks in seven out of the ten identified human-related-procedures. These seven human-related procedures are equipment maintenance, abnormal situation treatment, human-machine interfaces, control-room monitoring, ground inspection, technical improvement, and manual operation. A summary of human factors and corresponding management methods to address them is provided in Table 3.

\section{Evaluations of human factor management methods}

Among human factors summarized in Table 3, working attitude, is the most influential one. However, the managers had the most disagreement with effective management methods on these factors.

\section{Interviewees' positions and their proposed methods}

To improve employees' working attitudes, managers from different levels prefer to deal with the elements shown in Fig. 4. All the five front-line managers in Company D stated that increasing salaries and benefits is a powerful way to make employees more responsible for, loyal to and satisfied with their work. They expressed the opinion that employees always try to adjust how much they do according to how much they get compensated. However, those front-line managers are not in the position to consider the financial situation of the plant as such decisions are defined by upper level management. Although none of the managers denied that giving more benefits to workers can be a useful and direct method to stimulate their working initiative, such measures are not strongly supported by higher level managers, because the latter have to consider the overall expenses of the entire operation.

Another common method of improving working attitudes seems to be the dynamic positioning of employees, which refers to moving employees up and down according to their performance over a period of time and making them more competitive in their careers. This method is considered by three of the mid-level managers in Company D as the most effective method to address employees' working attitude. It is also supported by seven managers from the other three companies. However, this approach has its own limitations, too; as stated by one manager (C-MM-7):

"When a technical worker has done an excellent job in his position, according to the dynamic positioning method, he should be upgraded to a management position; but he knows almost nothing about how to manage and it is not worth training him to take the place of a person who can manage and is already managing."

Two managers felt that personality contributes to responsibility, loyalty, and carefulness. As B-SM-3, a senior manager, suggested:

"Rewards can be helpful for persons who are rarely careless to make them try to reach a state of no-carelessness; punishment can be a powerful instrument to use on persons 


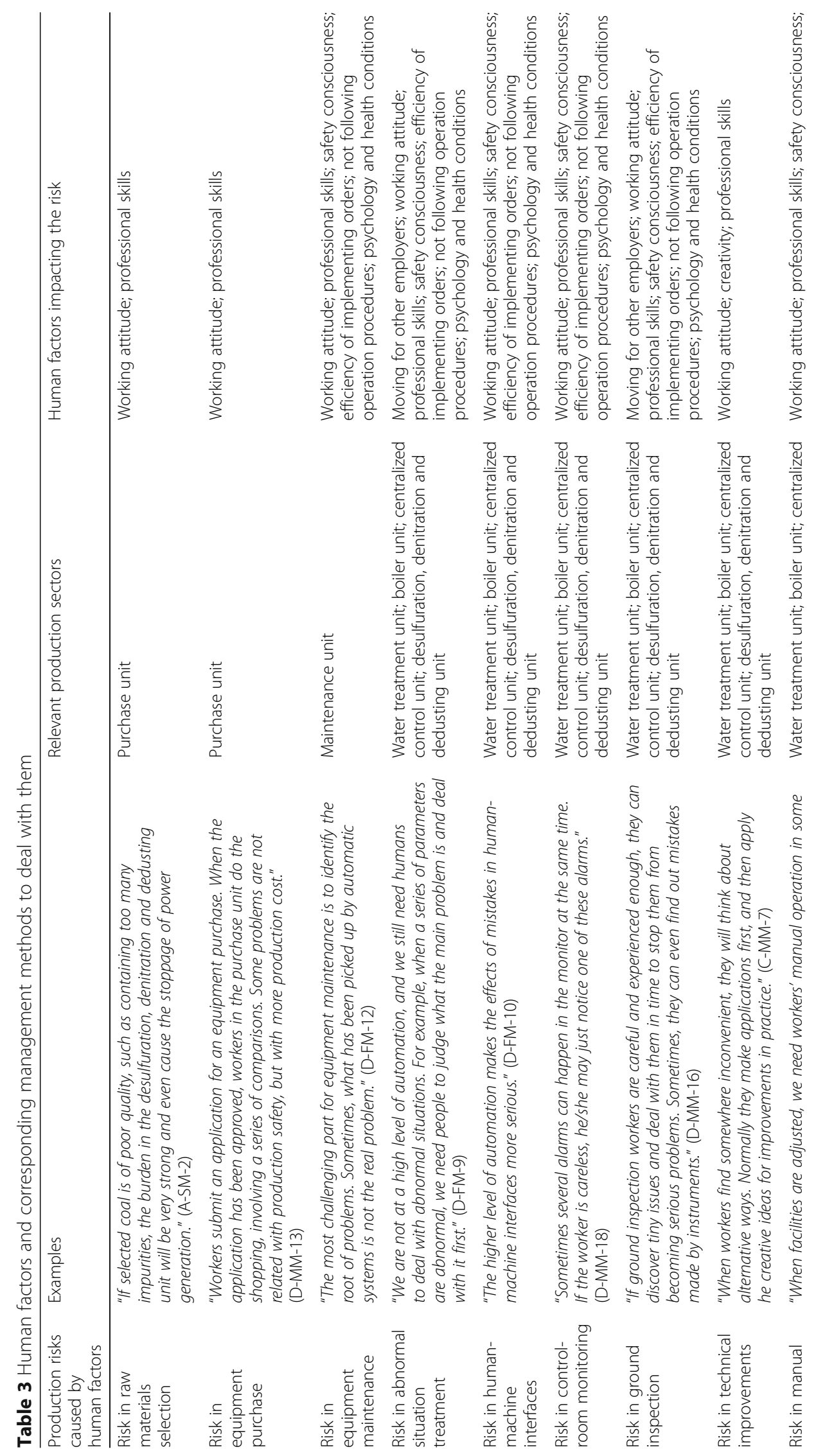




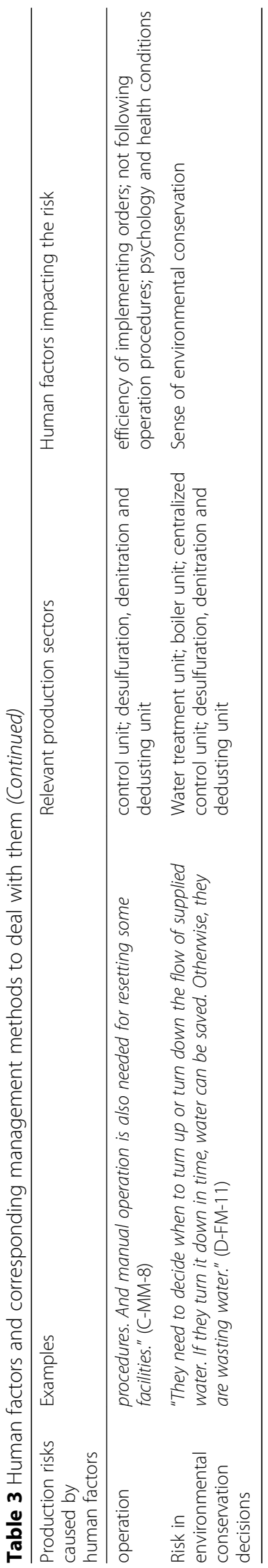


who sometimes are careless to make them reduce their carelessness; but almost nothing can be efficient for those who are always careless because it is the issue of personality."

Compared with some managers from other plants who mainly identify personnel by technical skills and academic degree ranks, middle level managers in Company D apply several ways to identify different personalities. For example, D-FM-14 said: "Sense of responsibility is related to how the person treats his/her family, and the salary requirement can express self-judgment and test whether the gap between his expectation and the real work situation is significant."

Different from middle level managers' methods for selecting suitable workers, the senior manager in Company D, D-SM-15, seeks other methods to deal with existing personnel. To improve employees' working attitudes, he has been developing a corporate culture that seeks to make the plant a family for personnel. Not only is the working attitude shared by him and other personnel, but also the attitude towards daily life is shared by them all.

The above-illustrated gap between attitudes of different levels of management toward management methods for personnel's working attitude, in Company D, is confirmed by one manager, C-MM-7, in Company C. C-MM-7 stated that, staffs at different levels were concerned about different things. For example, front-line workers want to reduce workload, increase salary and get promotions, while managers want front-line workers to actively implement their jobs.

\section{Effectiveness of management methods on workers in different generations}

The family-like corporate culture in Company D has been shown to work especially well for older personnel. One of the experienced front-line managers, D-FM-12, emotionally stressed that he was touched by the senior manager's words and his way of leading. D-FM-12 felt that the senior manager cared very much about front-line workers. "Our senior manager said that two things could not be delayed: The first thing was to take care of your parents and the second was to educate your children".

Two reasons may make the "plant as a family" method useful for workers who give their service to the plant for many years. The first one is that the plant has been seen as a second family by those workers because they have been working for the plant for many years. So they feel close to those who treasure the plant. The other reason may be that due to their rich life and working experiences, they have similar feelings as senior management and they feel some kind of psychological connection with the plant. However, these two reasons cannot be the case for younger personnel, which may mean that the "plant as a family" method is not as effective for them. Eight younger managers in Company D stated that career development and benefits are more attractive than being part of a work-based "family."

To influence younger employees with the corporate culture and instill the feeling that the plant is a family, a method applied by one manager (C-MM-8) in Company $\mathrm{C}$, may be useful. Managers have one-to-one meetings with new employees and familiarize themselves with the new employees' career planning, help the latter 
set reasonable career goals, and help them understand the corporate culture more clearly.

\section{Discussion}

In this study, we explore how human factors, as a crucial input in production processes and as a source of production risk, influence output variability in thermal power plants and investigate corresponding management for those human factors. A summary of identified human factors and their influenced procedures is provided in Table 4.

Risks in raw materials selection, equipment purchase, equipment maintenance, abnormal situation treatment, human-machine interfaces, control-room monitoring, ground inspection, technical improvements, manual operations, and environmental conservation decisions are identified as production risks caused by human factors in thermal power plants. Among all identified risks, risk in abnormal situation treatment is identified as the most serious one, because once an abnormal situation cannot be properly treated, chain reaction could make things worse.

Corresponding human factors for the identified production risks include workers' professional skills, working attitude, turnover, creativity, safety consciousness, efficiency of implementing orders, violating operation procedures, psychological and health conditions, and environmental awareness. Influenced by personality, corporate culture, welfare, salary, dynamic position management, and the gap between expectations and real work situations, working attitude is the most influencing human factor, followed by professional skills which are determined by experiences and knowledge.

By targeting identified human factors, we also recognize a series of management methods for reducing negative effects and enlarging positive effects of these production risks. The effectiveness of those evaluated management methods varies with employees at different levels and in different generations.

Table 4 Human factors and corresponding production procedures

\begin{tabular}{|c|c|}
\hline Human factor & Related production procedures \\
\hline Professional skills & $\begin{array}{l}\text { Raw material selection; equipment purchase; equipment maintenance; abnormal } \\
\text { situation treatment; human-machine interfaces; control-room monitoring; ground } \\
\text { inspection; technical improvements; manual operation }\end{array}$ \\
\hline Working attitude & $\begin{array}{l}\text { Raw material selection; equipment purchase; equipment maintenance; abnormal } \\
\text { situation treatment; human-machine interfaces; control-room monitoring; ground } \\
\text { inspection; technical improvements; manual operation }\end{array}$ \\
\hline $\begin{array}{l}\text { Moving for other } \\
\text { employers }\end{array}$ & Abnormal situation treatment; ground inspection \\
\hline Creativity & Technical improvements \\
\hline Safety consciousness & $\begin{array}{l}\text { Equipment maintenance; abnormal situation treatment; human-machine interfaces; } \\
\text { control-room monitoring; ground inspection; manual operation }\end{array}$ \\
\hline $\begin{array}{l}\text { Efficiency of implementing } \\
\text { orders }\end{array}$ & $\begin{array}{l}\text { Equipment maintenance; abnormal situation treatment; human-machine interfaces; } \\
\text { control-room monitoring; ground inspection; manual operation }\end{array}$ \\
\hline $\begin{array}{l}\text { Violating operation } \\
\text { procedures }\end{array}$ & $\begin{array}{l}\text { Equipment maintenance; abnormal situation treatment; human-machine interfaces; } \\
\text { control-room monitoring; ground inspection; manual operation }\end{array}$ \\
\hline $\begin{array}{l}\text { Psychology and health } \\
\text { conditions }\end{array}$ & $\begin{array}{l}\text { Equipment maintenance; abnormal situation treatment; human-machine interfaces; } \\
\text { control-room monitoring; ground inspection; manual operation }\end{array}$ \\
\hline $\begin{array}{l}\text { Sense of environmental } \\
\text { conservation }\end{array}$ & Environmental conservation decisions \\
\hline
\end{tabular}




\section{Theoretical implications}

Our findings add to the human factors and production risk literature in three ways. First, by investigating human activities in the whole production process in thermal power plants, we find that besides the production risks in the situations well discussed in the literature, production risk in several other situations are also influenced by human factors. Some human factors related to production risks, identified by our study, are shown to be influential in other kinds of power plants. Namely, risk in abnormal situation treatment (Lee et al. 2012), risk in human-machine interfaces (Carvalho et al. 2008; Anuar and Kim 2014; Suwazono et al. 2015), and risk in control-room monitoring (Jou et al. 2011; Lee et al. 2012) have also been examined in nuclear power plants. Consistent with Sheikhalishahi et al.'s (2017) study on thermal power plants, we also find that human factors are sources of risk in equipment maintenance. Besides these previously examined production risks, thermal power plants, one of the least environmentally friendly power plants (Wolf 2015; van Kooten et al. 2016), offer us an opportunity to notice the importance of human factors in environmental conservation decisions. As these plants have less automated system controls than nuclear power plants, hydropower plants and wind power plants, we can also see ordinary workers' effects on risk in manual operations and technical improvements; where more procedures depend on human judgment, it emphasizes human factors' influence on production risks in raw materials selection, equipment purchase, and ground inspection.

Second, compared with previous studies, we find that several important human factors, which are sources of production risk, have not been well investigated in production research. Some identified human factors in our study are consistent with previous studies. Such human factors include: professional skills, based on knowledge and experience (Sheikhalishahi et al. 2017); turnover (Vaurio 2009); psychological and health conditions (Govindaraju et al. 2001) such as fatigue (Sheikhalishahi et al. 2017; Baayen et al. 2017), and mental pressure (Jou et al. 2011); violating operation procedures, related with procedure usage (Sheikhalishahi et al. 2017); and efficiency of implementing orders, relying on supervision quality and communication (Bevilacqua and Ciarapica 2018). In spite of their importance to production in thermal power plants, other human factors we identified in our study including working attitude, safety consciousness, creativity, and environmental awareness have not received much attention as potential sources of production risks. These unique findings greatly contribute to the literature on human factors' effect on operations.

Third, the negative effects of human factors in production receive the most attention from researchers (e.g., Carvalho et al. 2008; Theophilus et al. 2017; Sheikhalishahi et al. 2017; Bevilacqua and Ciarapica 2018; Xie and Guo 2018). Based on the interviews in this study, we find that there are potential positive impacts on production risks and sources of output variability (Tiedemann and Latacz-Lohmann 2013) from human factors, such as creativity and environmental awareness. Workers' creativity potentially contributes to technical or procedural improvements in production, and their sense of environmental conservation contributes to resource or energy saving during production procedures. While researchers should still be cognizant of negative aspects of human factors in production, we also draw scholars' attention to the positive effects. By focusing on positive effects, scholars could find more ways to improve the efficiency of production in thermal power plants and even other types of operations. 


\section{Practical implications}

Our study benefits management practice in thermal power plants in three ways. First, by linking human factors to production risks, investigating sources influencing these human factors, and evaluating management methods to address identified human factors, we show what can be done by front-line managers and middle level managers to manage their subordinates. It is difficult to combine human resource management into front-line production management, considering that human factors in production processes are not easily systematically identified, measured, and therefore, managed (Vogt et al. 2010). Human factors connect operations management and human resource management, in which managing human factors shapes a production system while human resource management chooses and promotes people who suit the system (Neumann and Dul 2010). Our study helps bring the two together by identifying human factors in each production sector and providing a series of corresponding management methods.

Second, by evaluating management methods with managers in different positions and different plants, we suggest effective methods to manage subordinates' working attitudes and creativity. We also find several factors influencing the effectiveness of identified methods. The first factor is the position of the managed personnel. Toor (2009) notices that gaps of knowledge and understanding exist between employers and employees, but our research finds those gaps also occur between different levels of management. Different methods used to manage people's working attitudes are chosen by front-line managers, middle level managers and senior managers, due to their different perspectives. Front-line managers are more concerned with workers' benefits but do not focus on the plant's overall operation. Middle level managers' focus is often confined to their departments, while senior managers need to consider all kinds of employees and the limited resources of the plant. The second factor is the age of the managed personnel. Young employees are more concerned with practical benefits, such as promotion or salary increase, while older employees are more likely to be attracted by methods that emotionally influence their working attitude. The third factor is the personality of the managed personnel. Employees' creativity relates to not only a company's improvements but also stability. The interviewees from different plants use different management methods to encourage creativity. When a plant is located in an area where residents are quite conservative, and almost all employees in the plant are local people, the plant needs a method to encourage employees to give useful suggestions to improve production. If the same method is used at another plant, where most employees have critical personalities, these methods could make employees more unsatisfied with their current situation.

Third, by identifying working attitude and safety consciousness as human factors potentially causing production risk in thermal power plants, we explore different characteristics of human factors in thermal power plants' production. With disasters in nuclear power plant, such as the ones at Three Mile Island, Chernobyl, and Fukushima (Friedman 2011), potential catastrophic consequences of production accidents are so well known by the public (Wolf 2015) that employees in nuclear power plants do not necessarily need more training or education on safety consciousness or what may happen if they behave improperly. However, working attitude and safety consciousness are among the most influencing human factors in production in thermal power plants. This 
is mostly because, as stated by some interviewees, A1, A6, A10, many workers in thermal power plants believe nothing serious could happen.

\section{Limitations and directions for future research}

Our study has several limitations which also point at potential avenues for future research. First, we use qualitative methods to analyze the importance of production risk and the contribution of human factors. Although the consistency and reliability of interview responses are tested during interviews, no quantitative assessment is involved in this research to test the validity of our interview responses. In the future, quantitative assessments can be used for more evidence in ranking the importance of each identified production risk as related to human factors.

Second, our interview sample may be considered to not be large enough to generalize the findings. In 2016, in the production and supply of electricity and heat, there were 7280 mid- to large-size plants in China (National Bureau of Statistics of China 2017). Only 18 managers from four companies were interviewed in this study. Although limited, our sample is still sufficiently representative considering that the majority of thermal power plants follow standard production procedures and have very similar structures. However, we still recommend a larger scale investigation to see if more human factors influencing production risks can be found. Third, in this study we find that managers from different levels hold different attitudes on risk management methods, but we have not investigated front-line workers' opinions to examine whether front-line managers consider risks and risk management from a worker's or manager's point of view. Future studies can look at workers' conceptualization of production risks and human factors and at risk communication between employees in different positions with one another and with the management level.

\section{Conclusion}

The purpose of this study is to investigate production risks caused by human factors in thermal power plants. Based on 18 interviews with plant managers, several production risks and related human factors are identified and the effectiveness of management methods for human factors influencing production risks applied in practice are evaluated. As one of the first studies examining human factors' effect on risk in environmental conservation decisions, manual operation, technical improvements, raw materials selection, equipment purchase, and ground inspection, our study emphasizes working attitude, safety consciousness, creativity and sense of environmental conservation as essential human factors potentially causing production risks in thermal power plants. Offering a series of corresponding management methods to deal with identified human factors, we provide insights in introducing human resource management into production management.

\section{Appendix}

\section{Sample guiding questions}

This appendix covers general questions designed for semi-structured interviews. A few specific questions were adapted and added according to particular conversations.

(1) What risks may be involved in thermal power plants? 
(2) What production risks can be caused by human factors?

(3) What jobs in production procedures need to be done by people?

After the previous questions, questions were asked according to the jobs identified by managers. To each job, the following questions were asked.

(4) What factors may influence people's working performance in this job?

(5) How likely is it that this production procedure is influenced by people?

(6) What may be caused by differences in performance by people in this job?

(7) Can you remember any real case about this production procedure being influenced by people in the past?

(8) Do you think there is any related human job?

The following questions were asked according to each human factor identified in answer to the fourth question.

(9) What sources may influence this human factor?

(10) What methods have been used to manage this factor?

(11) How efficient is the method?

(12) Do you think it is worth managing the factor?

(13) Can you remember a real case when a similar problem has been solved?

(14) What other methods can you suggest to deal with that factor?

(15) How likely do you think that method will be useful?

Acknowledgements

This case study was partially supported by the National Natural Science Foundation of China (No. 71472184). The authors would like to thank Dr. Tiejun Ma for his helpful comments and express their gratitude to all interviewees for their cooperation. The authors also thank the two anonymous reviewers for their constructive comments.

\section{Funding}

This study was partially supported by the National Natural Science Foundation of China (No. 71472184). The funding body facilitates the authors' data analysis and writing.

\section{Availability of data and materials}

We did not record the interviews, because most participants did not feel comfortable being recorded as production risk seem to be a sensitive topic for them. However, we have notes taken during the interviews and complemented with extra personal notes after each interview. We also have production training materials of the case study company. Finally, throughout analysis, we used Microsoft Visio to produce figures to show procedures and relationships between risks and outcomes. We have converted these images to JPEG files, but with MS Visio, we can provide editable figures too.

\section{Authors' contributions}

HD proposed the study and carried out the data collection and analysis. MG participated in the design of the study and helped the data analysis. Both the authors drafted, revised the manuscript, and read and approved the final manuscript.

\section{Competing interests}

The authors declare that they have no competing interest.

\section{Publisher's Note}

Springer Nature remains neutral with regard to jurisdictional claims in published maps and institutional affiliations.

Received: 22 June 2017 Accepted: 6 July 2018

Published online: 06 August 2018

References

Abadie, L. M., \& Chamorro, J. M. (2009). Income risk of EU coal-fired power plants after Kyoto. Energy Policy, 37(12),

5304-5316 
Amato, A., Compare, M., Gallisto, M., Maccari, A., Paganelli, M., \& Zio, E. (2011). Business interruption and loss of assets risk assessment in support of the design of an innovative concentrating solar power plant. Renewable Energy, 36(5), 1558-1567.

Amir-Heidari, P., Farahani, H., \& Ebrahemzadih, M. (2015). Risk assessment of oil and gas well drilling activities in Iran-a case study: Human factors. International Journal of Occupational Safety and Ergonomics, 21(3), $276-283$.

Antle, J. M. (1983). Incorporating risk in production analysis. American Journal of Agricultural Economics, 65(5), 1099-1106.

Anuar, N., \& Kim, J. (2014). A direct methodology to establish design requirements for human-system interface (HSI) of automatic systems in nuclear power plants. Annals of Nuclear Energy, 63, 326-338.

Arab, M., Bidin, N., Chaudhary, K., \& Hosseinian, R. (2015). Characterization of pollution indices in soil surrounding a power plant by laser induced breakdown spectroscopy. Analytical Letters, 48, 360-370.

Baayen, H., Vasishth, S., Kliegl, R., \& Bates, D. (2017). The cave of shadows: Addressing the human factor with generalized additive mixed models. Journal of Memory and Language, 94, 206-234.

Bevilacqua, M., \& Ciarapica, F. E. (2018). Human factor risk management in the process industry: A case study. Reliability Engineering and System Safety, 169, 149-159.

Carvalho, P. V. R., Santos, I. L. D., Gomes, J. O., Borges, M. R. S., \& Guerlain, S. (2008). Human factors approach for evaluation and redesign of human-system interfaces of a nuclear power plant simulator. Displays, 29(3), $273-284$.

Chang, S. Y., Li, D. C., \& Chen, T. L. (2010). Using an electronic product code network to improve monitoring systems for continuous operating equipment-A thermal power plant example. Proceedings of the Institution of Mechanical Engineers Part B Journal of Engineering Manufacture, 224(9), 1437-1445.

Chavas, J. P., Chambers, R. G., \& Pope, R. D. (2010). Production economics and farm management: A century of contributions. American Journal of Agricultural Economics, 92(2), 356-375.

Chen, T. T., \& Wang, C. H. (2017). Fall risk assessment of bridge construction using Bayesian network transferring from fault tree analysis. Journal of Civil Engineering and Management, 23(2), 273-282.

Chidambaram, P. (2016). Perspectives on human factors in a shifting operational environment. Journal of Loss Prevention in the Process Industries, 44, 112-118.

Dan, J. R. G., Arnaldos, J., \& Darbra, R. M. (2017). Introduction of the human factor in the estimation of accident frequencies through fuzzy logic. Safety Science, 97, 134-143.

Derksen, M. (2014). Turning men into machines? Scientific management, industrial psychology, and the "human factor". Journal of the History of the Behavioral Sciences, 50(2), 148-165.

Feili, H. R., Akar, N., Lotfizadeh, H., Bairampour, M., \& Nasiri, S. (2013). Risk analysis of geothermal power plants using failure modes and effects analysis (FMEA) technique. Energy Conversion and Management, 72, 69-76.

Friedman, S. M. (2011). Three Mile Island, Chernobyl, and Fukushima: An analysis of traditional and new media coverage of nuclear accidents and radiation. Bulletin of the Atomic Scientists, 67(5), 55-65.

Govindaraju, M., Pennathur, A., \& Mital, A. (2001). Quality improvement in manufacturing through human performance enhancement. Integrated Manufacturing Systems, 12(5), 360-367.

Islam, M. S., \& Nepal, M. (2016). A fuzzy-bayesian model for risk assessment in power plant projects. Procedia Computer Science, 100, 963-970.

Ji, Y., Huang, G. H., \& Sun, W. (2015). Risk assessment of hydropower stations through an integrated fuzzy entropyweight multiple criteria decision making method: A case study of the Xiangxi River. Expert Systems with Applications, 42, 5380-5389.

Jou, Y. T., Yenn, T. C., Lin, C. J., Tsai, W. S., \& Hsieh, T. L. (2011). The research on extracting the information of human errors in the main control room of nuclear power plants by using performance evaluation matrix. Safety Science, 49, $236-242$.

Karki, R., Thapa, S., \& Billinton, R. (2012). A simplified risk-based method for short-term wind power commitment. IEEE Transactions on Sustainable Energy, 3(3), 498-505.

Krishnasamy, L., Khan, F., \& Haddara, M. (2005). Development of a risk-based maintenance (RBM) strategy for a powergenerating plant. Journal of Loss Prevention in the Process Industries, 18(2), 69-81.

Lavasani, S. M., Zendegani, A., \& Celik, M. (2015). An extension to fuzzy fault tree analysis (FFTA) application in petrochemical process industry. Process Safety and Environmental Protection, 93, 75-88.

Le Bot, P. (2004). Human reliability data, human error and accident models - Illustration through the three Mile Island accident analysis. Reliability Engineering \& System Safety, 83(2), 153-167.

Lee, S. W., Park, J., ryum Kim, A., \& Seong, P. H. (2012). Measuring situation awareness of operation teams in NPPs using a verbal protocol analysis. Annals of Nuclear Energy, 43, 167-175.

Leenstra, M. (2017). The human factor in development cooperation: An effective way to deal with unintended effects. Evaluation and Program Planning In Press.

Li, W., Du, W., \& Yin, J. (2017). Digital entrepreneurship ecosystem as a new form of organizing: The case of Zhongguancun. Frontiers of Business Research in China, 11, 5. https://doi.org/10.1186/s11782-017-0004-8.

Liu, Y., Hu, X., \& Feng, K. (2017). Economic and environmental implications of raising China's emission standard for thermal power plants: An environmentally extended CGE analysis. Resources, Conservation and Recycling, $121,64-72$.

Majoumerd, M. M., Raas, H., Jana, K., De, S., \& Assadi, M. (2017). Coal quality effects on the performance of an IGCC power plant with $\mathrm{CO}_{2}$ capture in India. Energy Procedia, 114, 6478-6489.

Miles, M. B., \& Huberman, A. M. (1994). Qualitative Data Analysis: An Expanded Sourcebook (2nd ed.). California: Sage Publications, Inc..

National Bureau of Statistics of China. 2017. China Statistical Yearbook 2017. [Online]. Available: http://www.stats.gov.cn/ tjsj/ndsj/2017/indexeh.htm. Accessed 19 Jan 2018.

Neumann, W. P., \& Dul, J. (2010). Human factors: Spanning the gap between OM and HRM. International Journal of Operation \& Production Management, 30(9), 923-950.

Ofori-Parku, S. S. (2016). "Whale deaths" are unnatural: A local NGOs framing of offshore oil production risks in Ghana. Science Communication, 38(6), 746-775. 
Orme, G. J., \& Venturini, M. (2011). Property risk assessment for power plants: Methodology, validation and application. Energy, 36(5), 3189-3203.

Parkinson, D. K., \& Bromet, E. J. (1983). Correlates of mental health in nuclear and coal-fired power plant workers. Scandinavian Journal of Work, Environment \& Health, 9, 341-345.

Potluri, S. S., \& Rajan, T. A. (2010). Merchant power plants in India: Risk analysis using simulation. International Journal of Energy Sector Management, 4(1), 87-112.

Ramesh, V., \& Saravannan, R. (2011). Reliability assessment of a co-generation power plant in a sugar mill using fault tree analysis. Energy Sources, Part A: Recovery, Utilization, and Environmental Effects, 33(12), 1168-1183.

Ren, T., Li, Y., Fang, D., \& Li, H. (1998). Comparative health risk assessment of nuclear power and coal power in China. Journal of Radiological Protection, 18(1), 29-36.

Rodriguez-Iruretagoiena, A., Fdez-Ortiz, d. V. S., Gredilla, A., Ramos, C. G., Oliveira, M. L., Arana, G., et al. (2015). Fate of hazardous elements in agricultural soils surrounding a coal power plant complex from Santa Catarina (Brazil). Science of the Total Environment, 508, 374-382.

Rohrer, R. J., \& Nierode, C. F. (1996). Simple method for risk assessment of nuclear power plant refueling outages. Nuclear Engineering and Design, 167(2), 193-201.

Saunders, M., Lewis, P., \& Thornhill, A. (2009). Research Methods for Business Students (5th ed.). Harlow: Pearson Education Limited.

Sheikhalishahi, M., Azadeh, A., Pintelon, L., \& Chemweno, P. (2017). Human factors effects and analysis in maintenance: A power plant case study. Quality and Reliability Engineering International, 33(4), 895-903.

Smith, C. L. (1998). Calculating conditional core damage probabilities for nuclear power plant operations. Reliability Engineering \& System Safety, 59(3), 299-307.

Sobhani, A., Wahab, M. I. M., \& Neumann, W. P. (2017). Incorporating human factors-related performance variation in optimizing a serial system. European Journal of Operational Research, 257, 69-83.

Suwazono, T., Nakamura, N., \& Yamashita, A. (2015). Development of the remote-controlled platform truck for handling heavy object and the remote control human interface for the disaster response. Advanced Robotics, 29(3), 165-169.

Tanić, M. N., Janković-Mandić, L., Gajić, B. A., Daković, M. Z., Dragović, S. D., \& Bačić, G. G. (2016). Natural radionuclides in soil profiles surrounding the largest coal-fired power plant in Serbia. Nuclear Technology \& Radiation Protection, 31(3), 247-259.

Teperi, A. M., Puro, V., \& Ratilainen, H. (2017). Applying a new human factor tool in the nuclear energy industry. Safety Science, 95, 125-139.

Theophilus, S. C., Esenowo, V. N., Arewa, A. O., Ifelebuegu, A. O., Nnadi, E. O., \& Mbanaso, F. U. (2017). Human factors analysis and classification system for the oil and gas industry (HFACS-OGI). Reliability Engineering \& System Safety, 167, 168-176

Tiedemann, T., \& Latacz-Lohmann, U. (2013). Production risk and technical efficiency in organic and conventional agriculture-the case of arable farms in Germany. Journal of Agricultural Economics, 64(1), 73-96.

Toor, T. P. S. (2009). People management: An imperative to effective project management. Business Strategy Series, 10(1), 40-54.

van Kooten, G. C., Duan, J., \& Lynch, R. (2016). Is there a future for nuclear power? Wind and emission reduction targets in fossil-fuel Alberta. PLoS One, 11(11), e0165822.

Vaurio, J. K. (2009). Human factors, human reliability and risk assessment in license renewal of a nuclear power plant. Reliability Engineering \& System Safety, 94(11), 1818-1826.

Verbruggen, A. (2008). Renewable and nuclear power: A common future? Energy Policy, 36(11), 4036-4047.

Vogt, J., Leonhardt, J., Koper, B., \& Penning, S. (2010). Human factors in safety and business management. Ergonomics, 53(2), 149-163.

Vollmer, E., Hermann, D., \& Mußhoff, O. (2017). Is the risk attitude measured with the Holt and Laury task reflected in farmers' production risk? European Review of Agricultural Economics, 44(3), 399-424.

Wang, F. (2010). The evolution of hierarchy toward heterarchy: A case study on Baosteel's managerial systems. Frontiers of Business Research in China, 4(4), 515-540.

Wang, S., Wahab, M. I. M., \& Fang, L. (2011). Managing construction risks of AP1000 nuclear power plants in China. Journal of Systems Science and Systems Engineering, 20(1), 43-69.

Ward, S. (2005). Risk management: Organisation and context. London: Witherby \& Co. Ltd.

Wolf, R. (2015). Why wealthy countries must not drop nuclear energy: Coal power, climate change and the fate of the global poor. International Affairs, 91(2), 287-301.

Xie, X., \& Guo, D. (2018). Human factors risk assessment and management: Process safety in engineering. Process Safety and Environmental Protection, 113, 467-482.

Yan, S., Yan, S., \& Zhang, M. (2009). Manifestation of gender discrimination in the process of human resources development-A content analysis based on interview data. Frontiers of Business Research in China, 3(3), 470-491.

Yin, R. K. (2003). Case study research: Design and method (3rd ed.). London: Sage Publications Ltd..

Zhang, C., Wang, Y., Zheng, C., \& Lou, X. (2006). Exergy cost analysis of a coal fired power plant based on structural theory of thermoeconomics. Energy Conversion and Management, 47(7-8), 817-843.

Zhao, Z. Y., Zhu, J., \& Xia, B. (2016). Multi-fractal fluctuation features of thermal power coal price in China. Energy, 117, 10-18.

Zhou, J. L., Bai, Z. H., \& Sun, Z. Y. (2014). A hybrid approach for safety assessment in high-risk hydropower-constructionproject work systems. Safety Science, 64, 163-172. 